\title{
Effect of tele-health care on quality of life in patients with severe COPD: a randomized clinical trial
}

This article was published in the following Dove Press journal: International Journal of COPD

\author{
Oliver D Tupper' \\ Thorbjørn L Gregersen' \\ Thomas Ringbaek ${ }^{1,2}$ \\ Eva Brøndum' \\ Ejvind Frausing' \\ Allan Green' \\ Charlotte S UIrik ${ }^{1,2}$ \\ 'Department of Pulmonary Medicine, \\ Hvidovre Hospital, Hvidovre, \\ Denmark; ${ }^{2}$ Institute of Clinical \\ Medicine, University of Copenhagen, \\ Copenhagen, Denmark
}

Correspondence: Charlotte S Ulrik Department of Respiratory Medicine, Hvidovre Hospital, Kettegård Alle 30, DK-2650 Hvidovre, Denmark

Tel +45 2I623648

Email csulrik@dadlnet.dk
Background and objective: Telemonitoring (TM) of patients with COPD has gained much interest, but studies have produced conflicting results. We aimed to investigate the effect of TM with the option of video consultations on quality of life (QoL) in patients with severe COPD.

Patients and methods: COPD patients at high risk of exacerbations were eligible for the 6-month study and a total of 281 patients were equally randomized to either TM (n=141) or usual care $(n=140)$. TM comprised recording of symptoms, oxygen saturation, spirometry, and video consultations. Algorithms generated alerts if readings breached thresholds. Both groups filled in a health-related QoL questionnaire $\left(15 \mathrm{D}^{\circ}\right)$ and the COPD Assessment Test (CAT) at baseline and at 6 months. Within-group differences were analyzed by paired $t$-test.

Results: Most of the enrolled patients had severe COPD ( $86 \%$ with Global Initiative for Chronic Obstructive Lung Disease stage 3 or 4 and $45 \%$ with admission for COPD within the last year, respectively). No difference in drop-out rate and mortality was found between the groups, and likewise there was no difference in $15 \mathrm{D}$ or CAT at baseline. At 6 months, a significant improvement of 0.016 in $15 \mathrm{D}$ score ( $p=0.03$; minimal clinically important difference 0.015 ) was observed in the TM group (compared to baseline), while there was no improvement in the control group -0.003 ( $p=0.68$ ). After stratifying $15 \mathrm{D}$ score at baseline to $<0.75$ or $\geq 0.75$, respectively, there was a significant difference in the $<0.75 \mathrm{TM}$ group of 0.037 ( $p=0.001)$, which is a substantial improvement. No statistically significant changes were found in CAT score.

Conclusion: Compared to the nonintervention group, TM as an add-on to usual care over a 6-month period improved QoL, as assessed by the 15D questionnaire, in patients with severe COPD, whereas no difference between groups was observed in CAT score.

Keywords: COPD, tele-health care, video consultations, quality of life

\section{Introduction}

Trailing in the wake of decline of lung function in COPD patients, diminishing physical, emotional, and social functioning leads to a deterioration in quality of life (QoL). ${ }^{1}$ Furthermore, a substantial prevalence of psychological distress further adds to the considerable adverse effects on QoL. ${ }^{2,3}$

Telemonitoring (TM) may have the potential to alleviate some of the burdens that COPD places on patients QoL, not only by providing rapid medical intervention in the early phase of deterioration in the patient's condition, and by that prevent hospital admissions, but also a way of reducing costs and time spent in transportation. ${ }^{4}$

To date, TM has been assessed in several different designs and setups, but results are conflicting, though mostly negative. Review articles published to date have struggled 
in extracting significant conclusions and, as it goes, have recommended additional and more extensive studies..$^{5-7}$

Three large studies have examined TM as an alternative to either home or outpatient clinic visits, with differing results. Pinnock et $\mathrm{al}^{8}$ and Trappenburg et $\mathrm{al}^{9}$ published their findings from 2 large randomized studies with COPD patients and reported that TM had no significant effects on QoL. McDowell's et a ${ }^{10}$ reported from a large 2-center randomized trial that TM has a positive impact on health-related QoL and anxiety. As TM involves substantial healthcare costs and commitment, there is a need for well-designed longer-term studies with appropriate follow-up to determine whether it is suitable for widespread application. ${ }^{7,11,12}$ Further studies are, therefore, clearly needed in order to establish whether or not TM has clinically relevant impact on QoL in patients with COPD.

The present randomized study aimed to investigate the impact of TM with the option of video consultations on $\mathrm{QoL}$ in patients with severe and very severe COPD recruited from respiratory outpatient clinics.

\section{Patients and methods Eligible patients}

The NetKOL study was a randomized controlled trial recruited patients from 4 hospitals with specialized pulmonary wards in Copenhagen (Hvidovre, Bispebjerg, Herlev, and Amager Hospitals).

The target population were patients with severe and very severe, stable COPD at high risk of exacerbations and hospital admissions. The inclusion criteria were as follows:

1. A diagnosis of COPD defined according to the Global Initiative for Chronic Obstructive Lung Disease criteria ${ }^{13}$ (post-bronchodilator forced expiratory volume in 1 second $\left[\mathrm{FEV}_{1}\right] /$ forced vital capacity $\left.<0.7\right)$.

2. Post-bronchodilator $\mathrm{FEV}_{1}<60 \%$ of predicted (pred) value.

3. Hospital admission due to COPD exacerbation within the previous 36 months and/or prescribed long-term oxygen therapy (LTOT) due to chronic respiratory failure for at least 3 months.

4. Regularly scheduled visits to the respiratory outpatient clinics.

5. COPD judged by the study staff as the leading cause of disability.

6. Residents in 1 of 6 municipalities in the Copenhagen area and the catchment area of 1 of the 4 recruiting hospitals. The exclusion criteria were as follows:

1. An exacerbation of COPD within the 3 weeks before enrollment.
2. Unwilling to provide informed consent for participating in the study.

3. Unable to use a tablet computer.

4. Planned stay outside the catchment area for 2 weeks or more during the study period.

5. Inability to participate due to language barrier or cognitive disorders.

6. Impossible to setup a functioning telephone line.

In case of hospital admission, patients continued in the study immediately after discharge from the hospital.

\section{Patient recruitment and randomization}

Over a 6-month inclusion period, we identified 560 eligible patients, of whom $281(51.2 \%)$ patients gave written informed consent to study participation and were randomized to either TM or usual care (control group) with a 1:1 allocation for 6 months. Randomized patients were divided into 3 categories:

Group 1 - Hospital admission for COPD in the previous year.

Group 2 - Hospital admission for COPD in the past 3 years, but not within the year before enrollment.

Group 3 - LTOT regardless of the number of hospitalisations for COPD in previous years.

Block randomization was used to ensure equal numbers of patients from the 3 groups were allocated to TM and usual care.

\section{Standard management of COPD}

All trial patients were managed and treated according to national and international guidelines. Usual care included outpatient pulmonary rehabilitation for patients with $\mathrm{FEV}_{1}<50 \%$ predicted and Medical Research Council dyspnea score $\geq 3{ }^{14}$ and supported discharge to selected in-hospital patients to reduce the risk of early readmission. ${ }^{15}$

\section{Usual care group}

Patients were seen for scheduled visits at the outpatient clinics once or twice a year and for unscheduled visits as required. In case of acute respiratory problems, patients could contact the staff at the outpatient clinic Monday to Friday, during the daytime. Depending on their mobility, patients on LTOT were seen either at the outpatient clinics or at home by a respiratory care nurse.

\section{TM group (intervention group)}

Patients randomized to the TM group were not seen at regularly scheduled visits at the outpatient clinics during the 6-month study period, but unscheduled visits were arranged 
if the TM consultation was considered inadequate by the health care professional.

The TM equipment comprised a tablet computer with a web camera, a microphone, and measurement equipment (spirometer, pulse oximeter, and bathroom scale). Patients reported changes in dyspnea, sputum color, volume, and purulence on the tablet computer. Measurements, including lung function, oxygen saturation, and body weight, and video consultations, together with the other measurements, were conducted at regular intervals, ie, once a week for the first 4 weeks of the study period and then every 4 weeks. ${ }^{16}$ Consultations without video, but with the other measurements, were performed every week throughout the study period. Patients were free to carry out additional measurements at any time or phone the call center during open hours. The observations were transferred to the call center at each participant's local hospital and automatically categorized and prioritized (ie, coded green, yellow, or red), and aberrant measurements were responded to by the specialist nurse either by phone or video consultation and if relevant conferred with a respiratory specialist. All measurements were stored in a secured database; access was granted to the patient's general practitioner and the municipal's social and health workers.

A more detailed description of the design of the present study is given in Ringbaek et al. ${ }^{16}$

\section{Measurements of outcome variables}

To measure the QoL, we selected 2 questionnaires, the $15 \mathrm{D}^{\mathrm{c}}$ and the COPD assessment test (CAT). The 15D questionnaire is a standardized 15-dimensional self-administered generic questionnaire. It assesses mobility, vision, hearing, breathing, sleeping, eating, speech, excretion, activities (usual), mental function, discomfort and symptoms, depression, distress, vitality, and sexual activity. There are 5 levels of each area of assessment (scored 1-5), and the resulting score is between 0 and 1 . One is equal to perfect health and well-being; a score of 0 is equal to a state of death. ${ }^{17}$ The $15 \mathrm{D}$ questionnaire has previously been found to be comparable to the AQ20 score as a generic measure of health-related QoL. ${ }^{18}$ The CAT, a disease-specific health status questionnaire, provides a measure of disease severity from the patient's perspective. It contains 8 questions (cough, phlegm, chest tightness, breathlessness, activities, confidence, sleep, and energy) that pertain to a patient's COPD symptom burden. Each question consist of a 6-point differential scale, and the final score is between 0 and $40 .{ }^{19}$

\section{Outcomes and ethics}

The primary outcome was the change in health-related QoL as measured by the $15 \mathrm{D}$ questionnaire, with change in CAT score as the secondary efficacy parameter. Patients completed both questionnaires at baseline and again at 6-months (end of study period).

The study was approved by the Research Ethics Committee of the Capital Region of Denmark (H-4-2013-052).

\section{Statistics}

Data were analyzed with the statistical package SPSS version 24.0 (IBM Corporation, Armonk, NY, USA). The Fisher's exact test, unpaired $t$-test, and Mann-Whitney $U$ test were used, as appropriate, for comparisons between groups at baseline. For analyses of changes in $15 \mathrm{D}$ and CAT scores (including standard deviation), within-group differences were calculated using paired $t$-test. For between-group differences at follow-up, we calculated the values using analysis of covariance to account for baseline 15D and CAT scores. The 0.75 cut-point for $15 \mathrm{D}$ was based on the rounded median of the groups. A 2-sided $p$-value of $<0.05$ was considered significant.

\section{Results \\ Baseline characteristics}

A total of 207 COPD patients (85.7\%) enrolled in the study had an $\mathrm{FEV}_{1}<50 \%$ pred, 148 patients $(52.7 \%)$ had a Medical Resrach Council dyspnea score $\geq 4$, and 126 patients (44.9\%) had at least 1 hospital admission for COPD in the year before enrollment (Table 1). More females were allocated to TM; further comparisons between the 2 groups are given in Table 1.

\section{Study completion and withdrawals}

Four patients ( 3 in the TM group) withdrew their consent within the first 2 weeks of the study period, and 2 patients dropped out due to technical issues. Seventeen patients died during the study period, and 10 patients dropped out for other reasons (technical issues after the first 2 weeks or did not have the energy to carry on anymore). No significant differences in drop-out rates $(p=0.79)$ or mortality were found between the groups $(p=0.87)$.

\section{I5D QoL questionnaire}

In total, 140 patients in the TM group and 139 patients in the usual care group completed baseline CAT and the 15D questionnaire with no significant differences in scores between the 2 groups (Table 2). Of the enrolled patients, 123 from the TM group and 123 from the usual care group completed the follow-up assessment questionnaires at 6 months. We found a statistically significant $(p=0.03)$ within-group difference of 0.0162 by paired $t$-test in the TM group's change from 
Table I Baseline characteristics of the $28 \mid$ patients enrolled in the study and randomized to either TM ( $n=|4|)$ or usual care $(n=\mid 40)$

\begin{tabular}{|c|c|c|c|}
\hline Characteristics & TM group $(N=|4|)$ & Usual care group $(\mathrm{N}=\mid 40)$ & $P$-value \\
\hline Females, n (\%) & $86(61 \%)$ & $64(45 \%)$ & $0.0 \mathrm{I}^{\mathrm{a}}$ \\
\hline Age in years, mean (SD) & $69.8(9.0)$ & $69.4(10.1)$ & $0.75^{\mathrm{b}}$ \\
\hline $\mathrm{BMI}, \mathrm{kg} / \mathrm{m}^{2}$, mean $(\mathrm{SD})$ & $24.9(6.3)$ & $26.9(7.0)$ & $0.0 \mathrm{I}^{\mathrm{b}}$ \\
\hline FEV,$\%$ predicted, mean (SD) & $34.9(13.3)$ & $33.8(12.0)$ & $0.48^{\mathrm{b}}$ \\
\hline MRC dyspnea score, mean (SD) & $3.5(0.8)$ & $3.7(0.9)$ & $0.09^{c}$ \\
\hline Pack-years, mean (SD) & $42.9(26.4)$ & $4 I .0(22.7)$ & $0.72^{\mathrm{b}}$ \\
\hline LTOT, n (\%) & $37(26 \%)$ & $38(27 \%)$ & $0.86^{\mathrm{a}}$ \\
\hline Charlson comorbidity index, mean (SD) & $1.70(1.49)$ & $1.96(1.51)$ & 0.13 \\
\hline Living alone & $58 \%$ & $52 \%$ & $0.27^{c}$ \\
\hline $\begin{array}{l}\text { Number of hospital admissions for COPD } \\
\text { exacerbation last year, mean (range) }\end{array}$ & $0.91(0-7)$ & $1.22(0-23)$ & $0.61^{\mathrm{a}}$ \\
\hline
\end{tabular}

Note: aMann-Whitney $U$ test. 'Unpaired $t$-test. 'Fisher's exact test.

Abbreviations: BMI, body mass index; FEV , forced expiratory volume in I second; LTOT, long-term oxygen therapy; MRC, Medical Research Council; TM, telemonitoring.

baseline (Table 2). We found a statistically significant difference between groups at follow-up; the TM group had a higher mean 15D score of 0.0222 (95\% CI: 0.0023-0.0421, $p=0.03$ ) compared with the usual care group. There was a numerical, but statistically nonsignificant difference in CAT score at follow-up, and the TM group had a mean score of -0.59 (95\% CI: -1.86 to $0.67, p=0.36)$ lower than the usual care group.

After stratifying subjects by $15 \mathrm{D}$ score at baseline using a cut-off of 0.75 , we found a statistically significant withingroup difference in 15D in the TM group having a baseline score below 0.75 of 0.037 ( $p=0.001$ ). The 0.75 cut-point was chosen based on it being the rounded median for the groups. There was no significant change in 15D scores for the above $0.75 \mathrm{TM}$ group or both control groups.

\section{CAT}

There was no significant difference in CAT score between groups at baseline, though the TM group had a 1.6 point lower mean CAT score than the control group. There was no significant within-group change between baseline and follow-up in paired $t$-test. Both groups had a similar change in CAT score between baseline and follow-up (Table 3).

\section{Discussion}

The present randomized clinical trial revealed that TM with close contact between the patient and the health care providers at the hospital had a positive impact on QoL in patients with more severe COPD. To date, there have been multiple studies looking at the usefulness and potential application of TM. Results from these studies show that TM is not

Table 2 QoL, as assessed by the I5D ${ }^{\odot}$ score, at baseline, follow-up, as change within-group from baseline for the TM and usual care groups and difference at follow-up between TM and usual care

\begin{tabular}{|c|c|c|c|c|}
\hline & \multicolumn{2}{|l|}{ TM group $(N=|4|)$} & \multicolumn{2}{|c|}{ Usual care group $(N=\mid 40)$} \\
\hline I5D baseline, mean (SD) & \multicolumn{2}{|l|}{$0.735^{\mathrm{a}}(0.10 \mathrm{I})$} & \multicolumn{2}{|l|}{$0.726^{\mathrm{a}}(0.113)$} \\
\hline I5D 6-month follow-up, mean (SD) & \multicolumn{2}{|l|}{$0.76 \mathrm{I}^{\mathrm{b}}(0.107)$} & \multicolumn{2}{|l|}{$0.728^{c}(0.12 \mathrm{I})$} \\
\hline Within-group difference, mean & \multicolumn{2}{|l|}{$\begin{array}{l}0.016^{\mathrm{b}}(0.002-0.031)^{\mathrm{d}} \\
p=0.03^{\mathrm{e}}\end{array}$} & \multicolumn{2}{|c|}{$\begin{array}{l}-0.003^{c}(-0.018 \text { to } 0.012)^{d} \\
p=0.68^{e}\end{array}$} \\
\hline Between-group difference at follow-up, mean & \multicolumn{4}{|c|}{$\begin{array}{c}0.0222(0.0049-0.0622)^{\mathrm{d}} \\
p=0.02^{\mathrm{f}}\end{array}$} \\
\hline $\begin{array}{l}\text { TM + usual care groups stratified by } \\
\text { baseline I5D score }\end{array}$ & $<0.75(\mathrm{~N}=62)$ & $\geq 0.75(\mathrm{~N}=60)$ & $<0.75(\mathrm{~N}=7 \mathrm{I})$ & $\geq 0.75(\mathrm{~N}=52)$ \\
\hline I5D baseline, mean (SD) & $0.666(0.065)$ & $0.824(0.057)$ & $0.656(0.076)$ & $0.834(0.054)$ \\
\hline I5D 6-months follow-up, mean (SD) & $0.703(\mathrm{SD}=0.095)$ & $0.819(\mathrm{SD}=0.083)$ & $0.661(\mathrm{SD}=0.100)$ & $0.819(\mathrm{SD}=0.082)$ \\
\hline I5D change to 6-month follow-up, mean & $\begin{array}{l}0.037 \\
(0.016-0.059)^{d} \\
p=0.00 \mathrm{I}^{\mathrm{e}}\end{array}$ & $\begin{array}{l}-0.005 \\
(-0.024 \text { to } 0.013)^{d} \\
p=0.569^{e}\end{array}$ & $\begin{array}{l}0.006 \\
(-0.015 \text { to } 0.026)^{d} \\
p=0.588^{\mathrm{e}}\end{array}$ & $\begin{array}{l}-0.015 \\
(-0.037 \text { to } 0.007)^{d} \\
p=0.186^{\mathrm{e}}\end{array}$ \\
\hline
\end{tabular}

Notes: ${ }^{a}$ Nonsignificant difference. ${ }^{b}$ Only 122 patients completed follow-up I5D. 'Only 123 patients completed follow-up I5D. ${ }^{d} 95 \%$ confidence interval of the difference. ePaired $t$-test. ${ }^{f}$ Analysis of covariance.

Abbreviations: QoL, quality of life; TM, telemonitoring. 
Table 3 QoL, as assessed by the CAT score, at baseline, followup and as change within-group from baseline for the TM and usual care groups

\begin{tabular}{|c|c|c|}
\hline & $\begin{array}{l}\text { TM group } \\
(\mathrm{N}=141)\end{array}$ & $\begin{array}{l}\text { Usual care } \\
\text { group }(\mathrm{N}=140)\end{array}$ \\
\hline $\begin{array}{l}\text { CAT baseline, } \\
\text { mean (SD) }\end{array}$ & $26.9^{a}(6.7)$ & $28.5^{\mathrm{a}}(7.9)$ \\
\hline $\begin{array}{l}\text { CAT 6-month } \\
\text { follow-up, mean (SD) }\end{array}$ & $25.6^{\mathrm{b}}(6.9)$ & $27.5^{c}(7.5)$ \\
\hline $\begin{array}{l}\text { Within-group } \\
\text { difference, mean }\end{array}$ & $\begin{array}{l}-0.76 \\
(-1.68 \text { to } 0.15)^{d} \\
p=0.101^{\mathrm{e}}\end{array}$ & $\begin{array}{l}-0.73 \\
(-1.74 \text { to } 0.28)^{d} \\
p=0.154^{\mathrm{e}}\end{array}$ \\
\hline $\begin{array}{l}\text { Between-group } \\
\text { difference, mean }\end{array}$ & \multicolumn{2}{|c|}{$\begin{array}{c}(-1.86 \text { to } 0.67)^{d} \\
p=0.36^{f}\end{array}$} \\
\hline
\end{tabular}

Notes: aNonsignificant difference. 'Only 122 patients completed follow-up CAT. 'Only 123 patients completed follow-up CAT. ${ }^{d} 95 \%$ confidence interval of the difference. ${ }^{e}$ Paired $t$-test. 'Analysis of covariance.

Abbreviations: CAT, COPD Assessment Test; TM, telemonitoring; QoL, quality of life.

a clear-cut and straightforward solution that will improve all COPD patients' QoL, prevent exacerbations, and reduce hospitals costs. However, there are evident inclinations that TM will have a valuable place in specific, selected circumstances. The question is who can TM be beneficial to and in which areas can we expect TM to be successful? Based on our findings we will discuss the potential place for TM to improve QoL in selected severe and very severe COPD patients.

\section{Changes in QoL}

COPD patients in the TM group had a significant, but a small improvement in the QoL.

The minimum important change (MIC) in the 15D questionnaire has previously been evaluated by Alanne et al. ${ }^{20}$ They found the MIC of $15 \mathrm{D}$ to be \pm 0.015 and anchored the results to a 5-level subjective global assessment scale (1: much better, 2: slightly better, 3: much the same, 4: slightly worse, and 5: much worse) (Figure 1). The change seen in $15 \mathrm{D}$ score in the TM group equates, only just, to a

Minimally important differences in 15D score
1. Much better $=>0.035$
2. Slightly better $=0.015$ to -0.035
3. No change $=>-0.015$ to $\leq 0.015$
4. Slightly worse $=-0.035$ to -0.015
5. Much worse $=<-0.035$

Figure I Clinically significant changes in the $15 \mathrm{D}^{\odot} \mathrm{Q}$ oL score anchored to a global assessment scale of $\mathrm{I}-5$, by standardized algorithm transformed into an index from 0 to $I$.

Abbreviation: QoL, quality of life. global assessment score of 2 or slightly better. However, we find a group with potential for substantial improvement when selecting patients with a lower than median $(<0.75)$ QoL score as measured by the $15 \mathrm{D}$ questionnaire. The TM patients with a lower than median $15 \mathrm{D}$ score at baseline had a change equivalent to a global assessment score of 1 , or much better, at follow-up. The between-group difference equates to a clinically significant difference. However, there is at present no available study that has examined whether the MIC found by Alanne et $\mathrm{a}^{20}$ applies to between-group differences, but the assumption is that for now the same MIC applies.

Both McDowell et al ${ }^{10}$ with Saint George Respiratory Questionnaire (SGRQ) and Hospital Anxiety and Depression Scale (HADS) and Koff et a ${ }^{21}$ with, SGRQ found similar improvements in QoL, with a similar TM setup, where monitoring and follow-up are maintained by the same respiratory nurses. Pinnock et $\mathrm{al}^{8}$ found an improvement in QoL, but with no difference between treatment arms, ie, TM and control group. In this setup, information was only monitored by the study group, and in case of aberrant findings, they were relayed to the patient's general practitioner and action was at the GP's discretion. In our study and that of McDowell et al, ${ }^{10}$ monitoring was performed and followed up by the designated respiratory nurses in each center, in cooperation with a respiratory physician. Trappenburg et $\mathrm{al}^{9}$ used the clinical COPD questionnaire to determine the change in health-related QoL and found no significant effect of TM. The clinical COPD questionnaire score is based on the degree of symptoms and physical functioning, but not on aspects such as mood that is registered by the $15 \mathrm{D}, \mathrm{HADS}$, and SGRQ questionnaires. As we have found based on our patients' CAT score, TM has no significant effect on symptoms and functioning but improves when accounting for mood and outlook. We speculate that the reason we find a significant improvement, lies in the setup of the TM (that is very different between studies) with regular face-to-face or telephone interaction and follow-up action taken by the same team.

\section{Changes in CAT score}

We found no significant difference in CAT score between the TM and the usual care group at follow-up, and showed a similar nonsignificant decrease between baseline and 6-month follow-up. However, this is likely due to dropouts from the trial were patients with the highest baseline CAT score (median 30 for dropouts' vs 27 for completion to follow-up). Seeing as our intervention was merely monitoring and not for a new medicine or a new type of rehabilitation, it is not expected to improve symptom burden. 


\section{Conclusion}

Our findings suggest that TM has a potential role in improving the QoL of COPD patients overall, despite not improving symptoms and exacerbations, and not least in patients with a lower than median score of QoL. We found that patients who were randomized to TM in addition to usual care showed a clinically and statistically significant improvement in the QoL. Future studies should aim at determining the optimal cut-off point for 15D or other health-related QoL assessments for selecting TM candidates.

\section{Acknowledgments}

The authors wish to thank the NETKOL group (Pia Andersen, Lisbeth Østergaard, Christine Lilliedahl, Torben Lage Frandsen, Jo-Ann Ramsrud Jensen, Lene Nissen, Marie-Louise Pagh Søndberg, Tanja S Hansen, and Zofia Mikolaczyk) for data sampling and enthusiastic collaboration throughout the study period, and also, Jan Sørensen for help with the statistical analyses.

\section{Disclosure}

The authors report no conflicts of interest in this work.

\section{References}

1. Bentley CL, Mountain GA, Thompson J, et al. A pilot randomised controlled trial of a Telehealth intervention in patients with chronic obstructive pulmonary disease: challenges of clinician-led data collection. Trials. 2014;15:313.

2. Blumenthal JA, Emery CF, Smith PJ, et al. The effects of a telehealth coping skills intervention on outcomes in chronic obstructive pulmonary disease: primary results from the INSPIRE-II study. Psychosom Med. 2014;76(8):581-592.

3. Gudmundsson G, Gislason T, Janson C, et al. Risk factors for rehospitalisation in COPD: role of health status, anxiety and depression. Eur Respir J. 2005;26(3):414-419.

4. Wootton R. Twenty years of telemedicine in chronic disease managementan evidence synthesis. J Telemed Telecare. 2012;18(4):211-220.

5. McLean S, Nurmatov U, Liu JLY, Pagliari C, Car J, Sheikh A. Telehealthcare for chronic obstructive pulmonary disease. Cochrane Database Syst Rev. 2011;7:CD007718.

6. Cruz J, Brooks D, Marques A. Home telemonitoring in COPD: a systematic review of methodologies and patients' adherence. Int J Med Inform. 2014;83(4):249-263.
7. Gregersen TL, Green A, Frausing E, Ringbaek T, Brondum E, Suppli Ulrik C. Do telemedical interventions improve quality of life in patients with COPD? A systematic review. Int J Chron Obstruct Pulmon Dis. 2016;11:809-822.

8. Pinnock H, Hanley J, McCloughan L, et al. Effectiveness of telemonitoring integrated into existing clinical services on hospital admission for exacerbation of chronic obstructive pulmonary disease: researcher blind, multicentre, randomised controlled trial. BMJ. 2013;347:f6070.

9. Trappenburg JC, Niesink A, de Weert-van Oene GH, et al. Effects of telemonitoring in patients with chronic obstructive pulmonary disease. Telemed J E Health. 2008;14(2):138-146.

10. McDowell JE, McClean S, FitzGibbon F, Tate S. A randomised clinical trial of the effectiveness of home-based health care with telemonitoring in patients with COPD. J Telemed Telecare. 2015;21(2):80-87.

11. Goldstein RS, O'Hoski S. Telemedicine in COPD: time to pause. Chest. 2014;145(5):945-949.

12. Lilholt PH, Witt Udsen F, Ehlers L, Hejlesen OK. Telehealthcare for patients suffering from chronic obstructive pulmonary disease: effects on health-related quality of life: results from the Danish "TeleCare North" cluster-randomised trial. BMJ Open. 2017;7(5):e014587.

13. Vestbo J, Hurd SS, Agusti AG, et al. Global strategy for the diagnosis, management, and prevention of chronic obstructive pulmonary disease: GOLD executive summary. Am J Respir Crit Care Med. 2013;187(4): 347-365.

14. Fletcher CM, Elmes PC, Fairbairn AS, Wood CH. The significance of respiratory symptoms and the diagnosis of chronic bronchitis in a working population. Br Med J. 1959;2(5147):257-266.

15. British Thoracic Society Guideline Development Group. Intermediate care - Hospital-at-Home in chronic obstructive pulmonary disease: British Thoracic Society guideline. Thorax. 2007;62(3):200-210.

16. Ringbaek T, Green A, Laursen LC, Frausing E, Brondum E, Ulrik CS. Effect of tele health care on exacerbations and hospital admissions in patients with chronic obstructive pulmonary disease: a randomized clinical trial. Int J Chron Obstruct Pulmon Dis. 2015;10(1):1801-1808.

17. Sintonen $H$. The $15 \mathrm{D}$ instrument of health-related quality of life: properties and applications. Ann Med. 2009;33(5):328-336.

18. Mazur W, Kupiainen H, Pitkaniemi J, et al. Comparison between the disease-specific Airways Questionnaire 20 and the generic 15D instruments in COPD. Health Qual Life Outcomes. 2011;9:4.

19. Jones PW, Harding G, Berry P, Wiklund I, Chen WH, Kline Leidy N. Development and first validation of the COPD Assessment Test. Eur Respir J. 2009;34(3):648-654.

20. Alanne S, Roine RP, Rasanen P, Vainiola T, Sintonen H. Estimating the minimum important change in the 15D scores. Qual Life Res. 2015;24(3):599-606.

21. Koff PB, Jones RH, Cashman JM, Voelkel NF, Vandivier RW. Proactive integrated care improves quality of life in patients with COPD. Eur Respir J. 2009;33(5):1031-1038.
International Journal of COPD

\section{Publish your work in this journal}

The International Journal of COPD is an international, peer-reviewed journal of therapeutics and pharmacology focusing on concise rapid reporting of clinical studies and reviews in COPD. Special focus is given to the pathophysiological processes underlying the disease, intervention programs, patient focused education, and self management protocols.

\section{Dovepress}

This journal is indexed on PubMed Central, MedLine and CAS. The manuscript management system is completely online and includes a very quick and fair peer-review system, which is all easy to use. Visit http://www.dovepress.com/testimonials.php to read real quotes from published authors. 